\title{
Staff development at RMIT: bottom-up work serviced by top-down investment and policy
}

\author{
Carmel McNaught and Paul Kennedy \\ Royal Melbourne Institute of Technology, Australia \\ email: carmel.monaught@rmitedu.oc
}

Effective staff development is the weaving together of many strands. We need to support staff in their current work, while providing them with ideas, incentives and resources to look for new ways to design learning environments which will enhance student learning. Staff development must be combined with specific projects where change is occurring. Ideas are not hard to find. Incentives and resources are another matter. The paper will outline some general principles for effective staff development. These principles will be applied in the description of the substantial investment RMIT has made in order to realize our teaching and learning policy. We have a model of 'grass-roots' faculty-based work funded by large-scale corporate 'investment'. 'Bottom-up' meets 'top-down'.

\section{Educational design as the key to successful flexible learning}

What is the business of a university in the 1990s and 2000s? Quantity and quality are both important considerations in modern universities as they seek to maintain important intellectual and physical spaces for their staff to pursue creative research and development, while at the same time needing to provide teaching for escalating numbers of students in all courses in order to shore up funding. These student cohorts have become increasingly diverse (McInnis, James and McNaught, 1995) with more part-time students and students from a greater variety of backgrounds. Flexible modes of delivery have been widely viewed as the prime way of meeting the challenges posed by this diversity. There has been a fair amount of naive equating of flexible delivery with production of online materials ('Plug them into the Web') and insufficient attention to the relationship between flexible modes of operation for students, the use of communication and information technologies, and the design of educationally sound learning environments (Kennedy and McNaught, 1997; Reeves and Reeves, 1997). However, there is no doubt that communication and information technologies will be a major part of future university planning, as several recent reports make clear (e.g. Yetton et al., 1997). 
Discussions about using technology for flexible learning often centre on variation in time and place access to learning experiences. But it must mean more, if we are to believe that technology can meaningfully enhance students' learning experiences. Looking at how we can cater for a variety of learning styles, for example, by offering a variety of learning activities and a variety of assessment strategies, is essential.

Good educational design is the key to successful flexible learning. Here at RMIT University we offer staff a set of online tools to assist them in refurbishing their subjects and courses. We explain the functionality of each of the tools in terms of student learning activities. Table 1 matches some student learning needs, with examples of the design of suitable student activities, with components of the online toolset. Several of the tools could be used for most of the activities; examples are used for simplicity.

\begin{tabular}{|c|c|c|}
\hline Student learning need & Examples of student activity & $\begin{array}{l}\text { Example of current RMIT } \\
\text { benchmark Distributed Learning } \\
\text { System (DLS) toolset component }\end{array}$ \\
\hline Information handling skills & $\begin{array}{l}\text { Web searching: } \\
\text { using electronic Library databases }\end{array}$ & \\
\hline Developing understanding & $\begin{array}{l}\text { Building links between information } \\
\text { from various sources; } \\
\text { problem-solving exercises }\end{array}$ & $\begin{array}{l}\text { Courselnfo/ BSCW } \\
\text { Question Mark }\end{array}$ \\
\hline Linking theory to practice & $\begin{array}{l}\text { Working with embedded media and } \\
\text { simulations in course material; } \\
\text { tutorial programs with feedback }\end{array}$ & $\begin{array}{l}\text { Courselnfo } \\
\text { Hybrid systems with } \\
\text { CD-Roms }\end{array}$ \\
\hline $\begin{array}{l}\text { Practising discussion } \\
\text { and argument }\end{array}$ & $\begin{array}{l}\text { Online debates using a threaded } \\
\text { discussion }\end{array}$ & WebBoard \\
\hline Practising articulation of ideas & $\begin{array}{l}\text { Role playing using a threaded } \\
\text { discussion; } \\
\text { sharing essays online }\end{array}$ & $\begin{array}{l}\text { WebBoard } \\
\text { BSCW }\end{array}$ \\
\hline $\begin{array}{l}\text { Rehearsing skills and } \\
\text { procedures }\end{array}$ & Online quizzes with feedback & Perception Question Mark \\
\hline Practising teamwork & Group projects & $B S C W$ \\
\hline $\begin{array}{l}\text { Leaming professional } \\
\text { practice }\end{array}$ & All of the above! & \\
\hline
\end{tabular}

(The student leaming need is based on Laurillard: $w w w 2 . o p e n . a c . u k / L T T O / i n t e r n a l / t s a a . h t m$ )

Toble 1: Functions of the RMIT DLS toolset

\section{Universities as organizations which support or hinder innovation}

In a recent investigation into the factors supporting the adoption of computer-facilitated learning (CFL) at Australian universities (McNaught, Phillips, Rossiter and Winn, forthcoming), three major themes emerged. These were policy, culture and support. The 
considerable overlap between and within these themes is illustrated in Figure 1. There needs to be a congruence of policy, culture and support factors if significant adoption of CFL strategies is to occur.

The policy theme looked at specific institutional policies, such as equity and intellectual property, the alignment of policy throughout the organization, the direction of policy change (bottom-up or top-down) and a number of strategic processes which flowed on from policies such as grant schemes. Culture incorporated factors such as collaboration within institutions, and personal motivation of staff to use CFL, as well as particular aspects of funding, staff rewards and time, leadership, teaching and learning models, and attitudes such as 'not invented here'. Support incorporated a whole gamut of institutional issues including IT, library and administrative infrastructure, professional development for staff, student support, educational and instructional design support for academic staff, funding and grant schemes, and IT literacy.

Several universal factors in relation to widespread use of CFL were identified:

- coherence of policy across all levels of institutional operations and specific policies which impact on CFL within each institution;

- intellectual property, particularly the role of copyright in emerging online environments;

- leadership and institutional culture;

- staff issues and attitudes, namely, professional development and training, staff recognition and rewards, and motivation for individuals to use CFL;

- specific resourcing issues related to funding for maintenance or updating of CFL materials and approaches, staff time release and support staff.

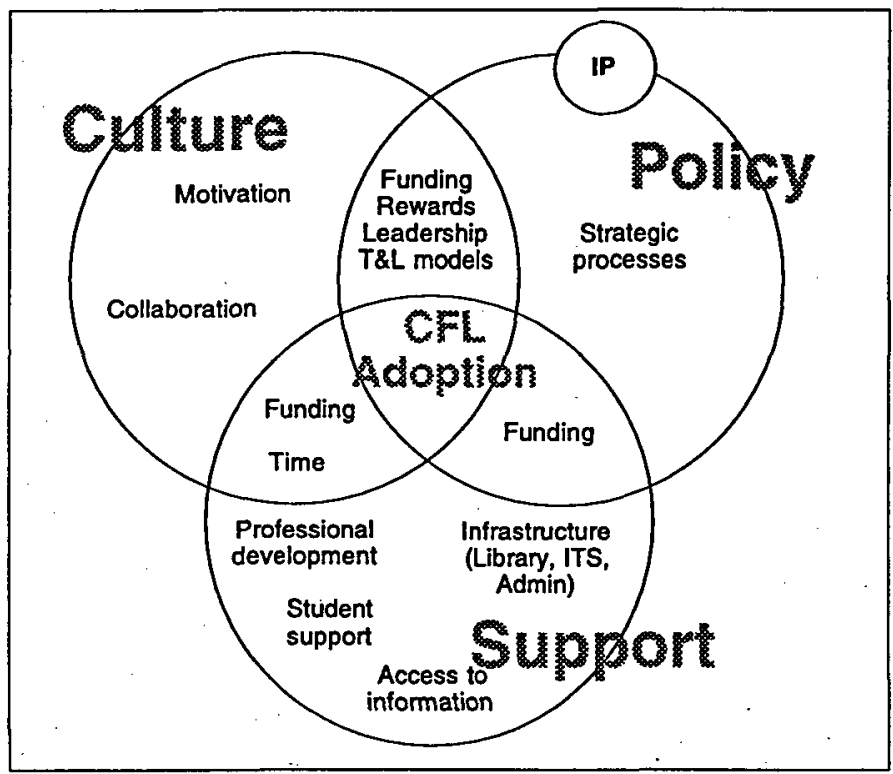

Figure 1: Themes and their relationships affecting the adoption of CFL 


\section{Staff development and training}

In all universities this is seen as a vitally important area. We should not underestimate the difficulties involved in innovation and change. Marris (1974) parallels the sense of loss during bereavement to the resistance one can feel when letting go of known ways of doing things and embarking on new strategies. For many academics the increasing emphasis on the use of computer technology for administration, research and teaching is highly threatening. We need to recognize these fears and devise plans which build staff confidence and motivation, and provide adequate support and training opportunities.

Staff development can no longer be a pleasant 'cottage industry' on the fringes of academe or the enthusiastic enterprise of a few individuals supported by 'soft' money. Effective staff development is positioned at the centre of university functioning and yet needs to retain connections with the needs and perceptions of teaching staff. This is a demanding challenge. Staff development programmes that are successful in meeting the needs of complex modern Australian universities need to be supported strategically (and financially) by their own universities.

Hughes, Hewson and Nightingale (1997), in a study of twenty Australian universities, describe three approaches to staff development for the use of information technology in teaching - integrated, parallel and distributed. These approaches are defined and the discussion in Hughes et al. is summarized in Table 2. In reality, universities use a combination of approaches, though with a trend in one direction. The table is useful as a tool for assessing the potential strengths and weaknesses of the combination of any particular set of support units in a given university

The number of players in the professional development area is large, including:

- 'Traditional' academic development units, concentrating on general teaching and learning support; these can be centrally located or in faculties.

- Units where the key focus is the use of communication and information technologies in teaching and learning. These can be centrally located or in faculties. They are often called flexible learning units.

- Units which focus on courseware production using technology. These can be centrally located or in faculties. Some of these units have evolved from print-based distance education units or centrally-based Information Technology Services units.

- University libraries.

Ellis, O'Reilly and Debreceny (1998) reported on an online survey of twenty academic development units ( 48 per cent response rate with a follow-up phone survey conducted of non-respondents) about staff development activities for technology in teaching and learning undertaken during 1997 and those planned for 1998. Results show that most of this type of staff development is still delivered by traditional methods such as classroom presentations, demonstrations and half-day tutorials while online methods of delivering staff development are less frequently used. The content of these courses covers a broad range of topics with the most popular being pedagogical issues in online course design, Web page design, and course authoring systems. Staff undertaking training tended to be from a cross-section of academic levels. Staff development activities of this nature are not 
Integrated Approach (eggs in one basket!)

Strong structural links between units or section of the one unit which provide generalT\&L support, support for using IT in T\&L, and production support for courseware. Essentially top-down.

Benefits:

Coherent policy framework

Efficient planning of resources and

avoidance of duplication.
Issues raised by.

Ease of access by all staff limited.

Individual approaches less likely to be

recognized.

An emphasis on one technological solution may emerge and overwhelm educational design.

Parallel approach (never the twain shall meet?)

Separate units for general T\&L support and support for using IT in T\&L

Benefits:

Allows due recognition to be given to a

wide range of T\&L issues (e.g internationalization) and

not just educational design associated with the use of $I T$.

Allows the development of expertise relating to the new technologies.
Issues raised by. Co-operation between the various units may be difficult to achieve. There is a potential for confusion and competition to emerge. May result in a narrow range of educational issues being addressed in the $T$ in T\&L units.

\section{Distributed approach (organic sprouting)}

More bottom-up than the other two approaches. A range of units, centrally located and in faculties which are not tightly co-ondinated. Project management remains with local projects.

Benefits:

An 'organic' solution where unnecessary controls do not hamper innovation.

Can be economical as skills are sought when they are needed.

\author{
Issues raised by. \\ Can result in weak project management where \\ there may be insufficient educational expertise. \\ Potential for innovations to falter without visible \\ institutional support. \\ Can result in waste and duplication of effort and \\ resources, including equipment.
}

Table 2: Integrated, parallel and distributed approaches to staff development for the usè of information technology in teaching (after Hughes et al., 1997)

exclusively provided by the academic staff development unit, but tend to be carried out by a range of internal and external providers, as noted above. The academic development units often play a key role in establishing and maintaining relationships between these units and the co-ordination of their activities is essential to the development of coherent and comprehensive staff development programmes.

McNaught et al. (forthcoming), identify six key issues in staff development:

- The appropriate balance point between centrally provided and local staff development services needs to be determined in each university. Central services can be more clearly 
linked to university priorities; faculty or department services can be more in touch with local needs.

- As technology becomes more mainstream, support services need to be scaled up. This involves deciding on the level of support that can be afforded and the model of support which is most apposite. The educational design and evaluation, technical, and media production support services that universities currently have are under strain. It is unlikely that the existing examples of good practice at each university will be sufficient to ensure that new or revised subjects will be well designed and evaluated. By modelling good practice themselves, mentors can assist staff to make optimal use of resources.

- A follow-on issue is determining the optimal relationship between staff development and production support services. Again, this needs to be decided in each university context.

- Even if an integrated model of professional development is adopted, there are still many professional development providers at most universities. Mapping the services of each provider and ensuring reasonable co-ordination is increasingly important as the need for support services scales up.

- Academic and general staff work load is a key issue. Careful work planning to ensure that staff have time to learn new skills and manage new processes is essential.

- We are in a time of rapid change. It is important that professional development support be flexible, appropriate and adaptable. It should make sense to staff, be linked to practice and be appropriately timed.

\section{Just how effective are academic development unit activities in supporting adoption of CFL?}

Figure 2 shows how staff in academic development units (ADUs) at Australian universities rate various activities in terms of how effective they believe each activity is in increasing the uptake of CFL in their university. The data in the survey in McNaught et al. (forthcoming) were represented by a five-point scale from 'very important' (5) through to 'not important' (1); the data have been collapsed into two categories - 'important' ( 4 and 5) and 'limited. importance' $(1-3)$ in order to see trends more clearly.

This can be compared with the responses of seventy-three members of ASCILITE (Australasian Society of Computers in Learning in Tertiary Education - the Australasian equivalent of ALT) - who rated how effective they believed each activity had been in supporting their use of CFL materials (Figure 3). The profiles are remarkably similar. Educational design and individual consultations are believed to be most important. However, as many ASCILITE members are innovators or early adopters (see Figure 4 below), this congruence between the perceptions of providers and clients must be tempered with the need to provide staff development across the whole range of staff expertise and interest. Indeed, coverage of support for all staff, not just the enthusiast teachers, has always been a major issue for academic development work. 


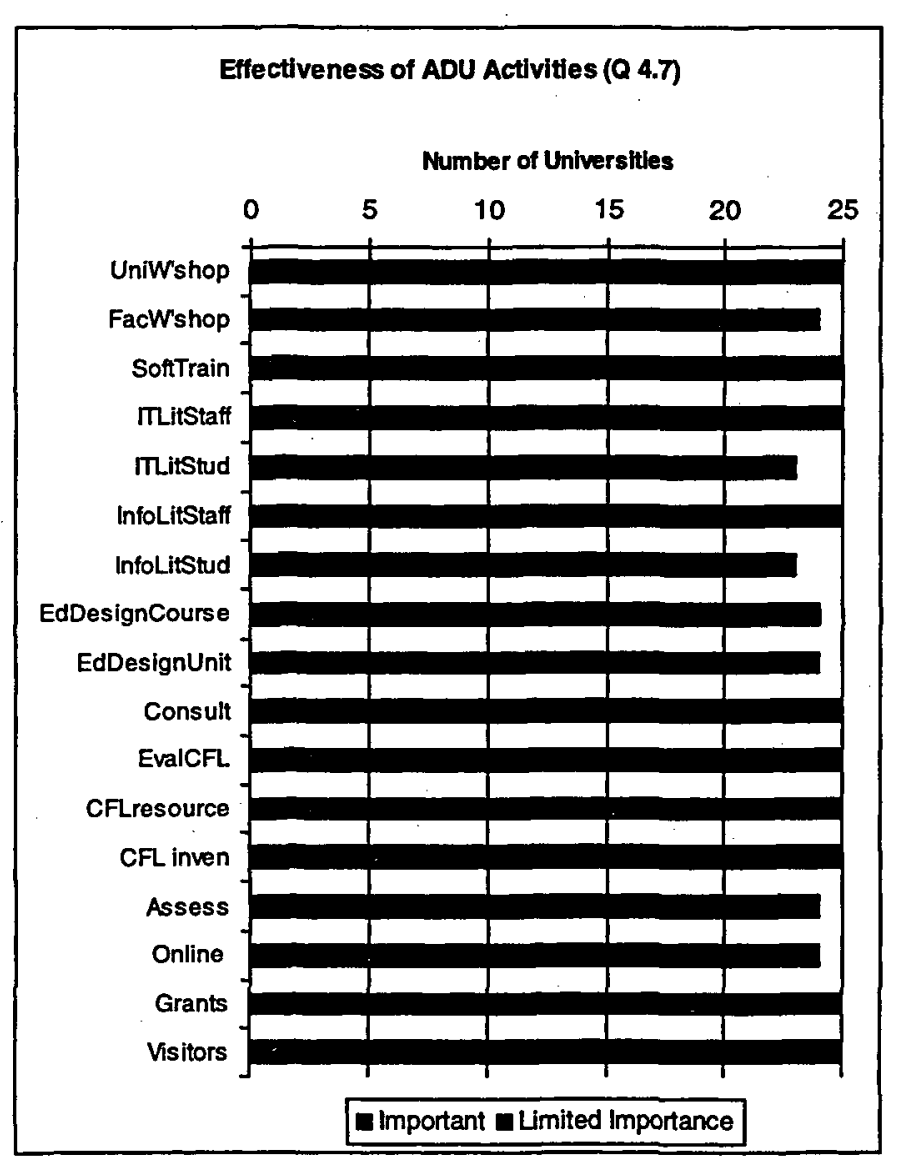

Key.

UniWshop: Generat workshops across the university

FacWshop: Faculty/ department workshops

Soft Train: Software training sessions

ITLitStaff: IT literacy support for staff

ITLitStud: IT literacy support for students

EdDesignCourse: Educational design of entire courses

EdDesignUnit: Educational design of units

Consult: Individual consultations

EvalCFL: Evaluation of computerfacilitated learning. (CFL) innovations

CFLresource: Providing information about CFL resources

CFLinven: Maintaining an inventory of CFL projects in the university

Assess: Support for computerbased assessment systems

Online: Support for online learning system

Grants: Facilitation of grant writing for CFL development

Visitors: Visiting specialists, teachers, scholars

Figure 2: ADU Assessment of effectiveness of various activities in supporting the uptake of CFL

\section{Are all staff being supported?}

A recent survey of ASCILITE members (McNaught et al., forthcoming) showed interesting data about the perceptions innovators or early adopters have about their colleagues. Most of the seventy-three members surveyed regarded themselves as innovators or early adopters (Figure 4) and many had developed significant projects single-handedly with little support from faculties or their university. These members were able to see the need for a well-supported environment for development. They were asked to categorize themselves on the scale:

- innovators;

- early adopters;

- users when technology is mainstream;

- very reluctant users. 
Key. See Figure 2. Note that ASCILITE members were not asked about the effectiveness of visiting speakers and scholars as several members work in this capacity themselves.

Figure 3: ASCILITE members' assessment

of effectiveness of various activities in supporting their uptake of CFL

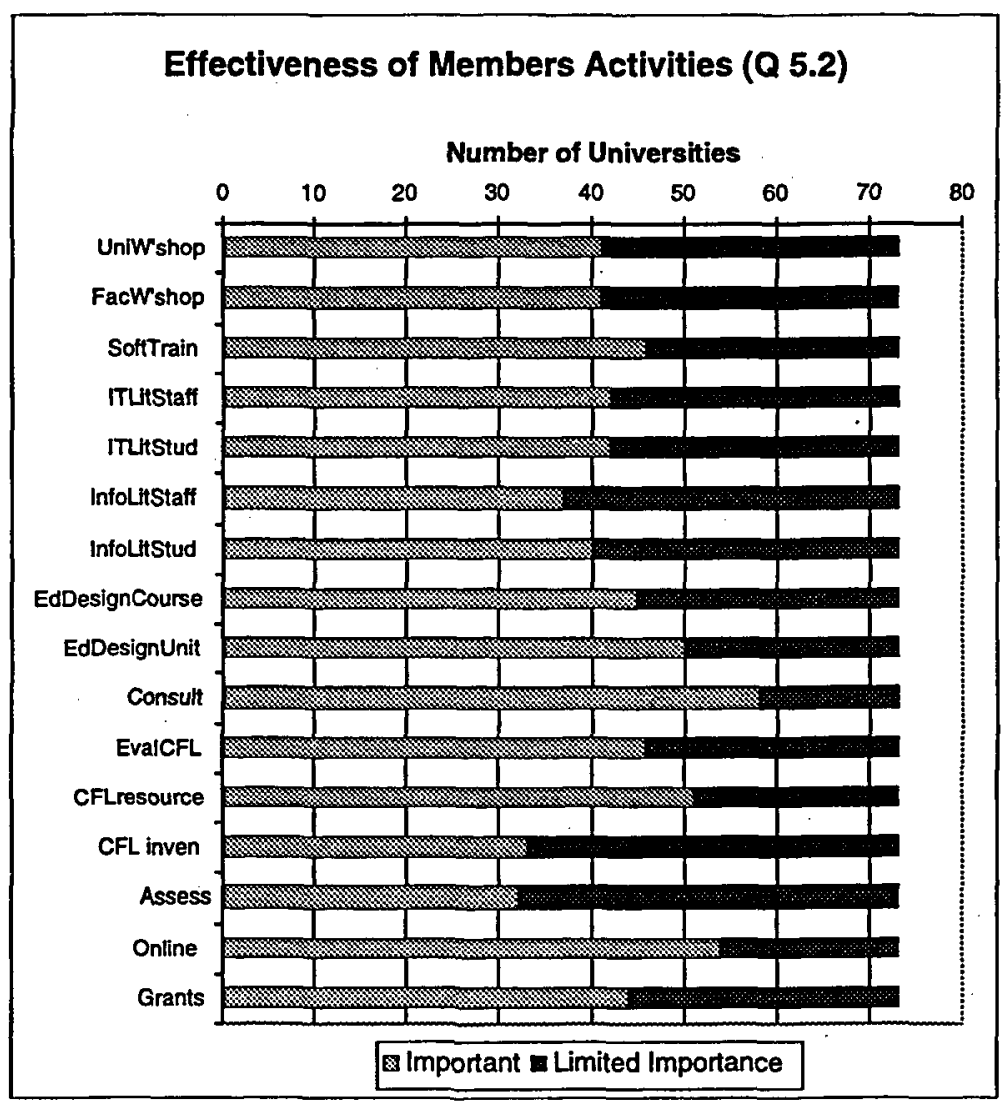

Figure 4: Schematic diagram of phases of technology take-up (after Rogers, 1995)

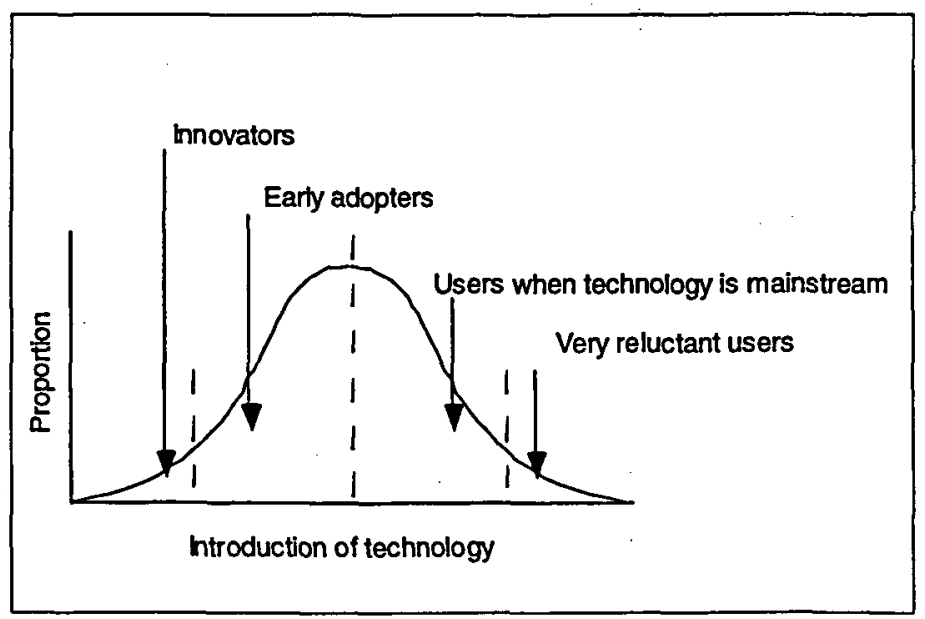

We also asked them to consider where the majority of staff in each category of department/faculty/ university were on this scale. The results are shown in Figure 5. The data from the survey were in four categories; the data have been collapsed into two 


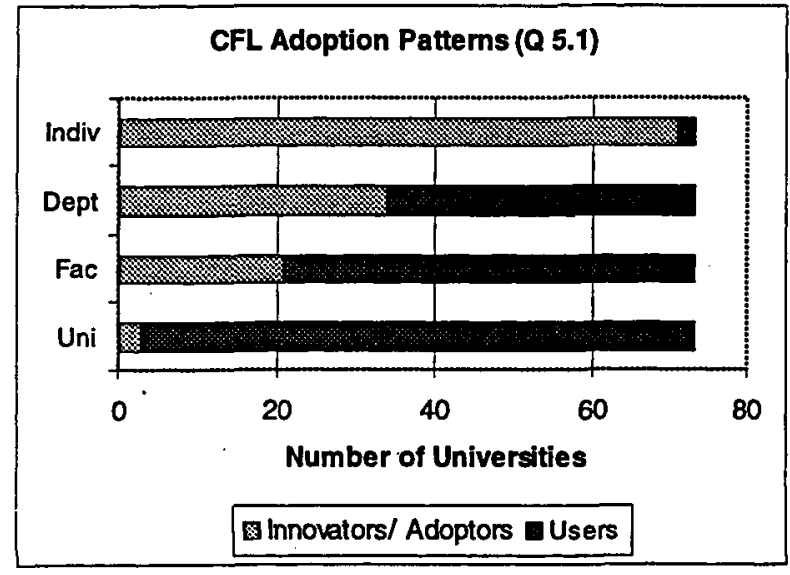

Figure 5: ASCIUTE members' perceptions of CFL adoption patterns at their universities

categories - innovators/ adopters and users/ reluctant users - in order to see trends more clearly. It is striking how isolated in many ways these innovators/early adopters are. The majority of respondent ASCILITE members considered themselves to be innovators or early adopters while they perceived that the majority of staff at their institutions only used technology when it was mainstream or were very reluctant users.

\section{How big are the staff development needs?}

Data obtained from Information Technology Services units at Australian universities provide insight into another issue relating to staff using computer-facilitated learning strategies. Figure 6 illustrates software support available to staff and their use of it. Note that while the respondent universities were all able to provide data about university infrastructure software support, many did not comment on staff and student use. It is clear that staff do not use the full range of technologies available to them. There are complex issues relating to culture, staff development and adequate provision of facilities at a local level that relate to the fact that the majority of Australian academics use their computers for email, Web-browsing and maybe basic Web teaching, and office applications (Word, PowerPoint and Excel). Also, it may be that some technologies will not be considered appropriate by the majority of staff and will not be used widely. Of course, it is heartening to note that many universities have set in place useful infrastructure for software support but, as indicated above, staff will use technology in their teaching when culture, policy and support structures are congruent.

\section{Applying these ideas to the context of RMIT University}

Universities in Australia are currently in an environment of intense change. They are being required to. educate more students, from an increasing variety of backgrounds, with decreasing government funding. Universities are required to compete vigorously for student enrolments and external sources of funding. In this environment, universities have had to reassess their fundamental business and the way they go about it. Information technology (IT) is viewed as an important factor in streamlining their operations. 
Figure 6: Software support available to staff and their usage.

Key: email, Web, telnet, ftp, synchronous chat, desktop videoconferencing, studio videoconferencing, streaming audio, streaming video, dial-up access, general

Office applications
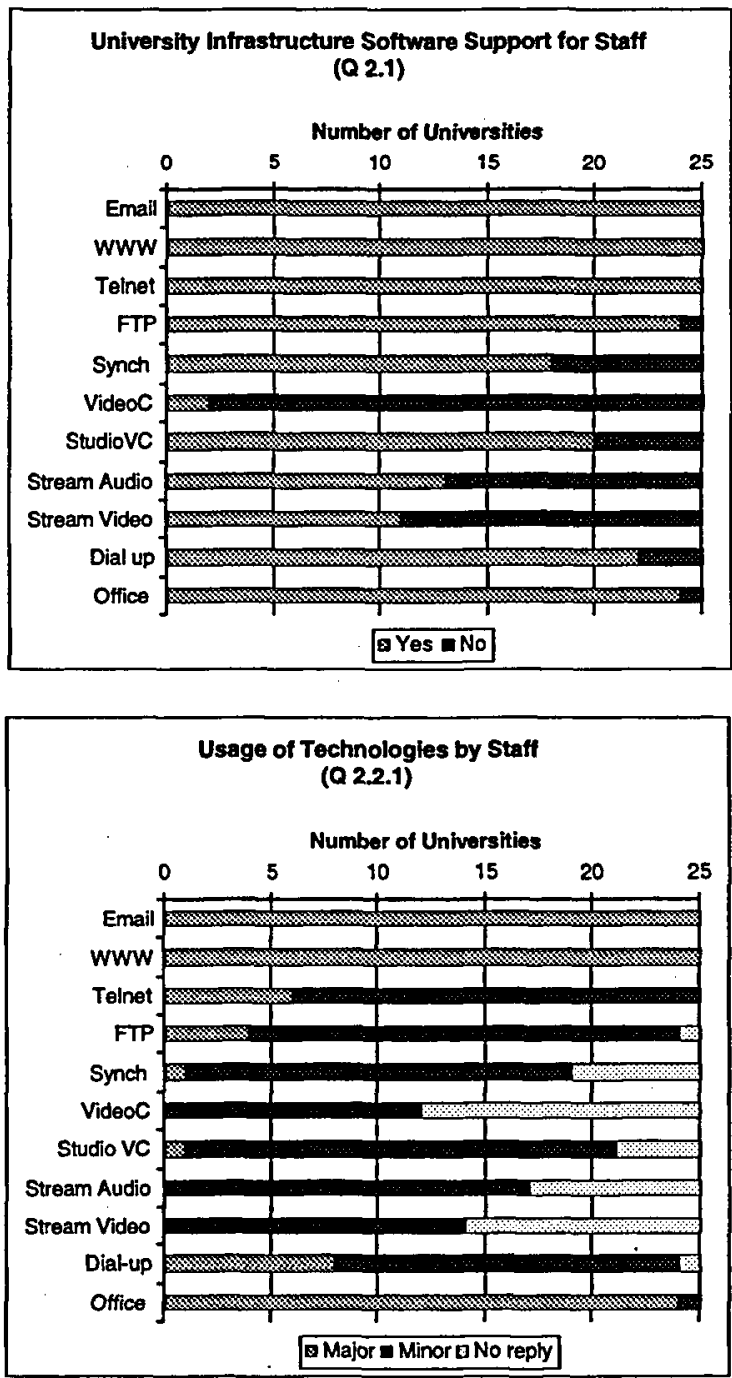

RMIT University is an 'old' (in Australian terms; RMIT began in 1887) technological university. It is highly diverse - it is a bi-sectoral (includes vocational sector) university and has the largest number of international students of any Australian university. There are seven strong faculties which often resist central directions. In recent years there has not been a strong staff development programme.

In the program which is described below, RMIT wanted staff development which:

- is linked to RMIT business and vision;

- promotes sound educational practice;

- ensures flexible learning is 'owned' in every department; 
- organizes adequate support for all staff;

- results in low increase in staff work loads.

There are two key policy documents which are currently guiding the direction RMIT takes for the next three to five years. The first is the Teaching and Learning Strategy (T\&LS).

\section{RMIT teaching and learning strategy}

The RMIT teaching and learning strategy aims to provide a student-centred learning environment where:

- subject programmes and the courses they comprise are designed to develop the following graduate attributes in students: knowledgeable, critical, responsible, creative and with a capacity for life-long learning, leadership and employability and an international outlook;

- the system is flexible enough to suit the particular learning needs of students in terms of their prior experience and current situation;

- courses are designed and implemented holistically with coherent connections between subjects comprising the core of a course;

- students and the community are seen as significant stakeholders;

- assessment is directly related to the explicitly stated objectives of subjects;

- quality improvement and quality assurance based on reflective practice and customerfocused systems design are ubiquitous.

There are resources allocated to implement the T\&LS both in human and financial terms. For example, each faculty has two senior positions established by secondment of academic staff members from within the faculty. Each faculty has a developing Faculty Education Services Group (FESG) where technical and educational support for staff is available.

\section{RMIT IT Alignment Programme}

RMIT University established a project team in 1998 to develop an Information Technology Strategy designed to facilitate the implementation of the objectives of the Teaching and Learning Strategy in respect of electronically mediated flexible learning environments. The RMIT Education and Training Alignment Project (ITAP) report (1998) delivered by the team in June 1998 and adopted by the University, forms the basis for a \$A50 million investment by RMIT over the next three years (1999-2001).

The report comprises several elements:

- IT infrastructure aligned with the needs of education to deliver the systems and hardware necessary to provide students with an electronically connected learning environment and access to computer-based learning resources;

- a Distributed Learning System (DLS) compliant with the emerging Educom/CAUSE Instructional Management System (IMS);

- a Student Management System (SMS), fully integrated with the DLS to provide enrolment and subject and course progress records electronically accessible to academics and students; 
- an extensive review of all academic processes within the university in a Business Process Re-engineering (BPR) project;

- extensive staff development.

\section{Enacting the RMIT teaching and learning strategy through the IT alignment project: designing the RMIT distributed learning system}

We have to deliver on our promise that we can provide a flexible set of tools that will enable staff who are not technological whizz kids to develop pedagogically sound, interesting, and relevant online courses in an efficient and well administered way. How have we designed our Distributed Learning System (DLS)? Here are some of our principles:

- a suite of tools, not just one;

- integrating educational principles into the description of the toolset;

- IMS compliance of all tools;

- a team approach to all online projects;

- involvement of all seven faculties in a benchmarking exercise to evaluate the toolset and the effectiveness of the learning environments we are building.

A learning-centred evaluation is being attempted. In order to set up a base-line for the teachers' reflections, teachers in each DLS project are asked to articulate the student learning outcomes for their subject and where they think the online experience would enhance learning. We ask all teachers to submit a weekly journal entry via an online feedback form to continue this process of reflection. It is quite difficult to extract this stream of continuous reflection from teachers (staff workload remains an issue), but several teachers do give us formal and informal feedback from time to time. As much of the informal anecdotal feedback is in email messages, the substance can be captured.

We also use the usual evaluation strategies with students of online questionnaires, focus groups, analysis of Web access data, analysis of support/ help desk records, and analysis of performance on learning outcomes. At this stage we really have only anecdotal evidence of learning enhancement (or otherwise).

Each semester we use a spreadsheet to collate the feedback data collected from staff and data received from staff and students from the DLS Help Desk. This is supplemented by data from student surveys conducted by individual subjects and reports from focus groups with students. The data are then coded using an iterative method whereby each discrete statement is assigned a descriptive category; these are then reviewed with some reduction of the number of categories occurring. For example, in Semester 1 of 1999 this process led to the identification of thirty-nine categories under which the comments were grouped. The categories were grouped under seven headings - access, toolset competence, support, student issues, educational outcomes, communication and miscellaneous. A report on the evaluation of Semester 11999 DLS subjects is given in McNaught, Kenny, Kennedy and Lord (1999). 


\section{Staff development through the Learning Technology Mentor Programme}

Approximately seventy Learning Technology Mentors have been appointed - one in each department of the university and some in central areas such as the Library. These are mostly academic and teaching staff who have funded one day a week time release to develop online materials and support their colleagues in their departments to engage with online teaching and learning. Initially this is a one-semester program but it will be extended in 2000 , giving some LTMs a further 26 days' time release, and bringing another cohort of 120 LTMs on board.

These LTMs undertake an extensive staff development programme about a week long. Some of the key topics are:

- RMIT's vision with respect to the university's position as a major international technological university. The Boyer (1990) Scholarship model has been used for some time as an integrating model for all RMIT work.

- The evolution of the Teaching and Learning Strategy over the last few years.

- The structure and function of the ITAP; description and key staffing of the ITAP Teams. Some comment on the importance of the Business Process Re-engineering (BPR).

- Course and subject renewal guidelines exist in all faculties and form a central focus of the T\&LS and the way in which ITAP works. The concept of graduate attributes is part of this process.

- Roles of the faculty-based Faculty Education Services Groups (FESGs). Relationship between FESGs and central ITAP Teams.

- Overview of the DLS toolset; how the use of the DLS tools relates to the renewal of subjects.

Additional staff development sessions are run each week. These sessions cover a range of practical 'hands-on' sessions and workshops in areas such as assessment and evaluation strategies for online learning, student induction methods, managing digital resources, project management, etc.

All LTMs develop a work contract with the first author who heads the Professional Development Team of the ITAP; if individual staff wish this can be formalized into accreditation for a subject in a Graduate Certificate of Flexible Learning.

We are seeing that staff development and support for developing online learning materials and strategies must become distributed across the organization. Therefore the role of the faculty-based Faculty Education Services Groups (FESGs) is pivotal. Growth needs to occur in these units rather than at the centre. We believe that technical support staff, educational designers and graphical designers are needed at faculty level and the only courseware production that should exist at the centre is some support for high-end media production and multimedia production. We are trying to combine the benefits of both the integrated and distributed approached mentioned earlier by Hughes et al. (1997). 


\section{Where to from here?}

We have a great deal of consolidation and development to do. We have been delighted by the enthusiasm of many Learning Technology Mentors. We have a sense of gathering momentum. In one year we have 190 subjects using the Distributed Learning System and many more in planning for use in 2000 . Several faculties are showing real commitment, though a couple might still need a persuasive nudge. Have we reached critical mass yet, where the appropriate use of technology will roll out across the University? Probably not, but we feel we are on the right track.

\section{References}

Boyer, E. L. (1990), Scholarship Reconsidered. Priorities of the Professoriate, Princeton, New Jersey: The Carnegie Foundation for the Advancement of Teaching.

Ellis, A., O'Reilly, M. and Debreceny, R. (1998), 'Staff development responses to the demand for online teaching and learning', in Corderoy, R. (ed.) FlexibillTy: The Next Wave? Proceedings of the Australian Society for Computers in Learning in Tertiary Education Conference, University of Wollongong, 191-201.

Hughes, C., Hewson, L. and Nightingale, P. (1997), 'Developing new roles and skills', in Yetton, P. (ed.), Managing the Introduction of Technology in the Delivery and Administration of Higher Education, Evaluations and Investigations Program report 97/3, Canberra: Australian Government Publishing Service, 49-79, http://www.detya.gov.au/highered/eippubs1997.htm.

Kennedy, D. K. and McNaught, C. (1997), 'Design elements for interactive multimedia', Australian Journal of Educational Technology, 13 (1), 1-22.

Laurillard, D., Technology strategy for academic advantage. Open University, UK, http://www2.open.ac.uk/LTTO/internal/tsaa.htm.

Marris, P. (1974), Loss and Change, London: Routledge \& Kogan Page.

McInnis, C., James, R. and McNaught, C. (1995), First Year on Campus, A commissioned project for the Committee for the Advancement of University Teaching. Canberra: Australian Government Publishing Service.

McNaught, C., Kenny, J., Kennedy, P. and Lord, R. (1999), 'Developing and evaluating a university-wide online Distributed Learning System: The experience at RMIT University', Educational Technology and Society, 2 (4),

http://ifets.gmd.de/periodical/vol_4_99/monaught.html.

McNaught, C., Phillips, P., Rossiter, D., and Winn, J. (forthcoming), Developing a Framework for a Usable and Useful Inventory of Computer-facilitated Learning and Support Materials in Australian Universities, Evaluations and Investigations Program report. Canberra: Higher Education Division Department of Employment, Education, Training and Youth Affairs.

Reeves, T. C. and Reeves, P. M. (1997), 'Effective dimensions of interactive learning on the World Wide Web', in B. H. Khan (ed.), Web-based Instruction, Englewood Cliffs, New Jersey: Educational Technology Publications, 59-66. 
RMIT Education and Training IT Alignment Project,

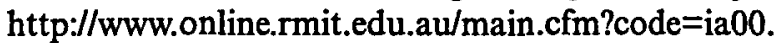

Rogers, E. M. (1995), Diffusion of Innovations, Fourth Edition, New York: The Free Press.

Yetton, P. and associates. (1997), Managing the Introduction of Technology in the Delivery and Administration of Higher Education, Evaluations and Investigations Program report 97/3. Canberra: Higher Education Division Department of Employment, Education, Training and Youth Affairs, http://www.deet.gov.au/divisions/hed/operations/eip9703/front.htm. 